\title{
Chromatin Fiber
}

National Cancer Institute

\section{Source}

National Cancer Institute. Chromatin Fiber. NCI Thesaurus. Code C13433.

A level of DNA packaging in chromatin above that of the nucleosome, the fundamental subunit of chromatin structure. The chromatin fiber has a thickness of about 30 nanometers and results from the folding of a linear array of nucleosomes (thickness about $10 \mathrm{~nm}$ ) into a more compact fiber. 